\title{
Tensile deformation behavior of dual-phase steels at elevated temperatures
}

\author{
N. Şen* \\ Department of Mechanical Engineering, Faculty of Engineering, Duzce University, 81620 Duzce, Turkey
}

Received 24 May 2019, received in revised form 8 July 2019, accepted 7 August 2019

\begin{abstract}
In this study, two distinct grades of commercial steel, DP600 and DP800, were thermo-mechanically tested relevant to mechanical behavior at five temperatures and two elongation rates. Some fundamental structural properties were also determined, including work (strain) hardening, strain rate sensitivity, and optimum ranges of forming temperatures. For both high-quality steels, tensile strength and flow stress noticeably decreased as work temperature increased. The maximum work hardening ratio for both strain rates was exhibited at $350{ }^{\circ} \mathrm{C}$ for DP600 and at $300^{\circ} \mathrm{C}$ for DP800. Deformation velocity effects for the DP600 occurred at $500{ }^{\circ} \mathrm{C}$, whereas they manifested at 400 and $500^{\circ} \mathrm{C}$ for DP800. In the warm deep drawing tests, the optimum forming temperature for DP 600 was $400^{\circ} \mathrm{C}$, while it was $450^{\circ} \mathrm{C}$ for DP800, taking into account the deformation velocity of both steels. It was concluded that a controllable and feasible manufacturing alternative is possible using local warm forming.
\end{abstract}

K e y w or d s: advanced high-strength (AHSS), DP600, DP800, tensile test, warm forming

\section{Introduction}

An important issue studied extensively in the automobile manufacturing sector is the production of lightweight and $\mathrm{CO}_{2}$-efficient automobiles and their components that exhibit high strength and long-lasting high quality throughout their service life as well as in the event of accidents [1]. At this point, dual-phase (DP) steels offer commanding solutions for the development of automobile components in all reasonable variants. Dual-phase steels are a grade (variant) of steels in the advanced high-strength (AHSS) steel family group with relatively straightforward alloying capabilities, lean processing and ferrite-martensite microstructure developing simplicity. They offer an excellent combination of ductility/hardness and formability, which makes them of interest to both automobile manufacturers and researchers. Dual-phase steels are produced through two different techniques. The first is via heat-treatment of low alloy steels at an intercritical temperature region, i.e., the $(\alpha+\gamma)$ region, followed by rapid quenching to a low temperature, generally room temperature (RT). The second way is the rolling method, in which steels are pro- cessed to the austenitic region temperature zone. After the rolling process, a heating step to the $(\alpha+\gamma)$ temperature zone is employed, followed by quenching $[2,3]$. Dual-phase steels have outstanding mechanical properties including a continuous yielding curve with no Lüders bands, a high-level combination of strength and softness and superior formability [4]. They are low-carbon steels containing a soft ferrite matrix and hard martensitic phases [5]. Essentially, the martensitic phase determines the strength of the steel, while the soft ferrite phase provides ductility [5]. Also, the strength of DP steels increases with the increase in the martensitic proportion [6]. For all these reasons, DP steels have been preferred extensively in the automotive industry for decades. The use of advanced high-strength steel has elevated passenger safety significantly and has led to a drop in fuel consumption as well as making vehicle production cleaner and greener by reducing vehicle weight. There is a wide range of DP types. The formability of DP steels is a common concern for researchers as they seek to find new methods for improving its benefits.

The mechanical behavior of the steels strongly depends on the deformation conditions that alter the

*Corresponding author: e-mail address: nurisen@duzce.edu.tr 
material microstructural formation. Hence, suitable deformation conditions must be introduced into the fabrication processes to achieve the desired mechanical properties. Here, tensile testing is the largely preferred mechanical testing method to reveal the mechanical properties of materials. In this testing approach, two basic elements, temperature and strain rate, are examined as determinative factors of mechanical behavior during deformation sequences. A review of current studies in the literature showed that Tsuchida et al. [7] investigated the effects of temperature and strain rate on the stress-strain mechanism of DP steels with varying carbon contents based on the Kocks-Mecking (KM) model. Khan et al. examined the quasi-static and dynamic responses of AHSS material strain rates ranging from $10^{-1}$ to $10^{3} \mathrm{~s}^{-1}$ at room temperature. Beynon et al. explored tensile and strain hardening properties of low-carbon dual-phase steels. Their goal was to calculate the crash performance of DP steels using low and rapid strain rates of $10^{-3}$ and $10^{2} \mathrm{~s}^{-1}$, respectively [8]. Oliver et al. compared DP steels to TRIP strip steels in terms of microstructural transformation by characterizing ferrite grain size and ferrite phase strain as well as the volume fraction of each phase as a result of quasi-static and dynamic tensile testing at low $\left(0.001 \mathrm{~s}^{-1}\right)$ and high $\left(200 \mathrm{~s}^{-1}\right)$ strain rates [9]. Darabi et al. conducted a micromechanical investigation of heat-treated DP800 and DP980 strip steels by comparing their flow curves with $2 \mathrm{D}$ and $3 \mathrm{D}$ micromechanical models dependent on symmetric and boundary conditions. Also, they studied the effect of martensite phase fraction in 2D and 3D micromechanical models by comparing two DP980 steel workpieces with distinct micromorphology as well as investigating localized strain patterns in the ferrite matrix [10]. Queiroz et al. observed the sensitivity of a DP steel to dynamic strain aging (DSA) via differentiating mechanical properties based on tension rate with altering temperature and strain rates. Their tensile tests were performed at temperatures ranging from 25 to $600^{\circ} \mathrm{C}$ and at strain rates varying between $10^{-2}$ and $5 \times 10^{-4} \mathrm{~s}^{-1}$. They detected characteristic indications connected to DSA, among which was a serrated flow for certain temperatures and strain rates. Maximum curves for tensile strength, strain hardening, and flow stress were provided by increasing temperatures [11]. Considering the observations of Queiroz, it is evident that recent studies have largely experienced serrations in the stress-strain curves as a common feature. Serrations have been revealed more clearly as a function of temperature and strain rates. The influence of DSA is inversely related to mechanical properties, causing contrary inclinations in the ductility kinetics as well as inconsistent formability properties.

Dynamic strain aging can occur in a wide range of steel grades, including DP strip steels, thereby increasing strength and reducing ductility as well as the ductile-to-brittle transformation temperature. The reduction in ductility performance arising from DSA has largely been investigated between 100 and $250^{\circ} \mathrm{C}$ by several researchers. Shahriary et al. found a rapid decrease in ductility at the DSA temperature in DP steels and introduced a quantitative solution for predicting DSA occurrence. The temperature zone was linked to the variants of tensile strength and flow stress of materials subjected to DSA. Queiroz et al. maintained that DSA had an impact on the material structure beginning from 25 to $600{ }^{\circ} \mathrm{C}$ and mostly at relatively low strain rates of $0.0001,0.001$, and $0.01 \mathrm{~s}^{-1}[2]$. They stated that the DSA mechanism was well controlled by confining the carbon constituent in the ferrite matrix via adjustment of the activation energy. However, DSA formation in DP steels may be more complex than in low carbon steels because of the distinguishing dual-phase microstructure consisting of a ferritic matrix and martensitic lamels. In the current literature, studies on DSA and resulting morphological properties have been conducted at relatively limited temperature rates. However, it is difficult to form DP steels at room temperature or relatively higher temperatures. Thus, it is necessary to employ a fairly high process temperature under the recrystallization temperature in a process referred to as warm forming. Some studies in the literature have addressed the determination of the mechanical properties of dual-phase steels carried out from room temperature $[1,6,12,13]$ to $300^{\circ} \mathrm{C}[14,15]$. In these studies, as a result of tensile tests of dual-phase steels up to $300{ }^{\circ} \mathrm{C}$, ultimate tensile strength (UTS) values were reported to be near to those tested at room temperature. Warm forming is among the most preferred methods for increasing the limiting drawing ratio (LDR) [16]. In the literature, accurate information regarding the mechanical performance of dual-phase steels at temperatures above $300{ }^{\circ} \mathrm{C}$ is insufficient. The present study aimed to determine the process temperature rates of the warm forming of DP600 and DP800 steels. Measurements including strain rate effect, hardening rate, ultimate tensile strength, and flow strength were assessed under different temperatures and strain rates.

\section{Experimental study}

\subsection{Materials}

Cold-rolled and tempered 1-mm-thick DP600 and DP800 steel sheets were purchased from SSAB (Swedish Steel Company). Their technical specifications and chemical compositions are given in Table 1 .

The specimens were prepared with the aid of a water jet. The typical steel workpiece technical specifications used in all laboratory experiments in this study are given in Fig. 1. Tensile testing procedures were 


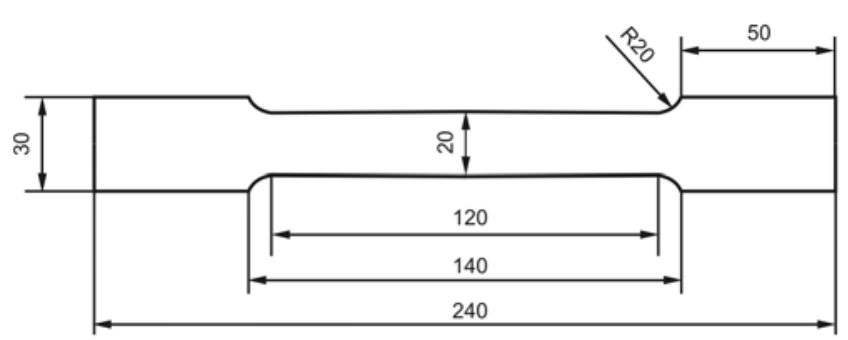

Fig. 1. Tensile test specimen dimensions.

implemented at 0.1 and $1 \mathrm{~s}^{-1}$ strain rates to analyze metallurgical and mechanical changes at different deformation rates.

\subsection{Method}

Microstructural images of both workpieces were captured using optical microscopy to differentiate each phase. Etching the samples using $2 \%$ Nital made it possible to contrast the ferritic matrix with the martensitic stripe-like structures. The microscopic images of the metal samples in Fig. 2 show the ferritic constituent bleached by the etching agent, while the black zones demonstrate the martensitic formation distributed throughout the lighter matrix. The mechanical properties of both specimens were tested following ASTM E-8 standard. The tensile test samples with the dimensions given in Fig. 1 were prepared in the rolling direction $\left(0^{\circ}\right)$ as the tests were carried out. Sheet thickness was $1 \mathrm{~mm}$ for both steel specimens. Mechanical properties may be altered in the preparation of tensile test specimens. To avoid this undesirable heat effect, a water jet machine was employed on the cutting material structure. As seen in many cases, the notch effect could disrupt the mechanical quality of the steel materials during deformation with detrimental results. Subsequently, an additional polishing procedure was carried out by sanding the test material surfaces to eradicate such side effects.

Mechanical properties of both specimens were determined by uniaxial tensile testing. Tensile tests were performed with a $100 \mathrm{kN}$ UTEST testing machine.

Constant stress rate and high-temperature tests were performed using a newly designed tensile test system. In this newly developed system, an induction heat apparatus was integrated into the tensile test machine chamber which made it possible to treat a restricted area (gauge length) in place of the overall length of the test specimen. The main advantage of this technique was that by only heating the gauge length out of the whole workpiece body, a wellobserved and precise strain measurement could be obtained from the test machine. By this method, advanced contours could be formed by facilitating the material flow locally without employing complicated deformation techniques. This innovation enabled a more realistic description of the material deforma-

Table 1. Chemical composition of DP600 and DP800 specimens

\begin{tabular}{cccccccccc}
\hline & \multicolumn{1}{c}{ Elemental composition (wt.\%) } \\
\cline { 2 - 8 } & $\mathrm{C}$ & $\mathrm{Si}$ & $\mathrm{Mn}$ & $\mathrm{P}$ & $\mathrm{S}$ & $\mathrm{Al}$ & $\mathrm{Nb}$ & $\mathrm{Ti}$ \\
\hline DP600 & 0.097 & 0.225 & 0.823 & 0.0123 & 0.0120 & 0.053 & 0.014 & 0.007 \\
DP800 & 0.141 & 0.214 & 1.483 & 0.0106 & 0.0156 & 0.085 & 0.018 & 0.009 \\
\hline
\end{tabular}
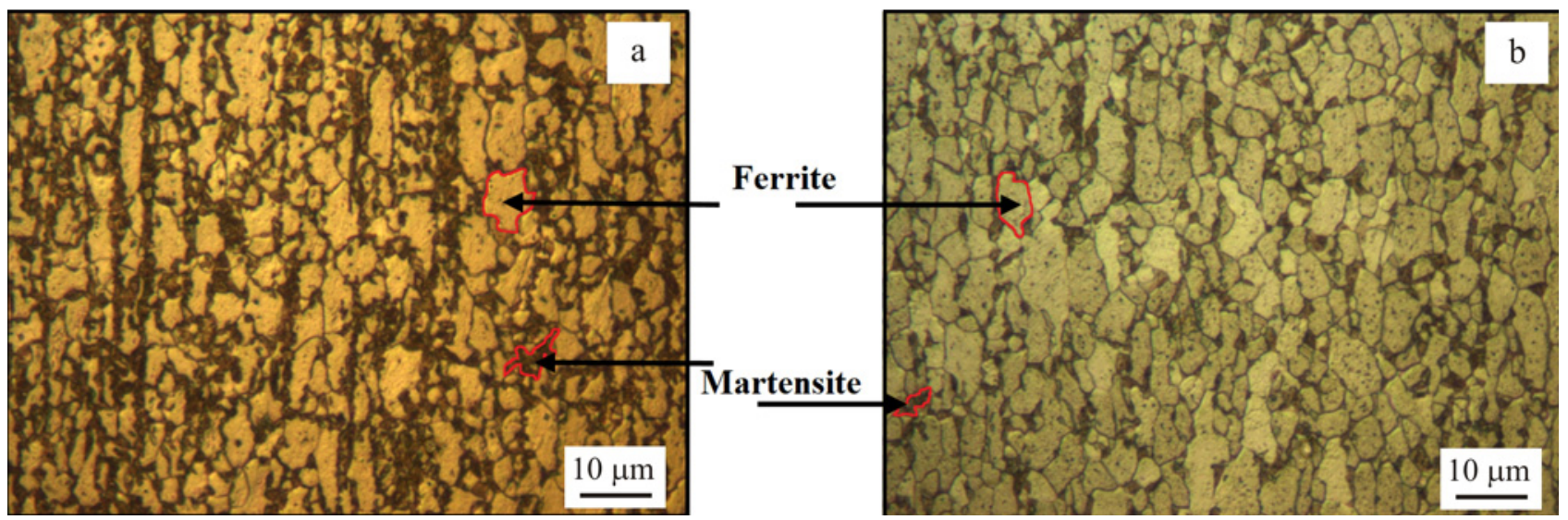

Fig. 2. The microstructure of dual-phase materials: (a) DP600 and (b) DP800. 


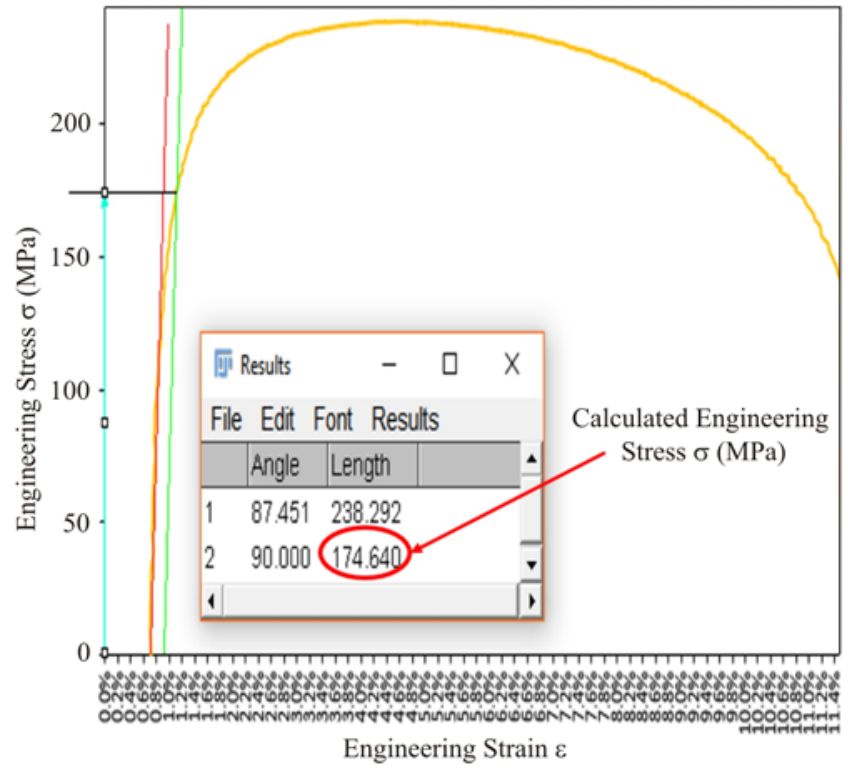

Fig. 3. Finding the yield point of DP 800 at $500{ }^{\circ} \mathrm{C}$ and $1 \mathrm{~s}^{-1}$ strain rate.

tion. The feasibility of this novel technique was examined through experimental and quantitative methods. Although the two local area heating techniques of induction and laser heating were available, in this study, induction heating was preferred due to its convenience, simplicity, and configurable characteristics. Along with the preferred heating method and deformation rate, the pristine condition and shape of the workpiece also had great importance in achieving the outcome.

A total of two laboratory experiments were carried out for each specimen for various strain rates and temperatures, as mentioned above. The mechanical properties of DP600 and DP800 steel specimens were determined on a tensile testing machine (UTEST) in the rolling direction $\left(0^{\circ}\right)$. The readings of load stress and total and uniform elongation were converted to engineering stress-strain graphs and are presented as such. The strength coefficient, work hardening exponent, and strain rate sensitivity were also calculated from the obtained reading sets of the stress-strain tests. Both specimens were fabricated via a water jet system. Dimensional specifications of the specimens were defined according to ASTM E-8 standards as given in Fig. 1. To heat the test specimens during laboratory experiments, the induction coil was rapidly induced to keep the microstructure and relaxation unchanged. The DP600 and DP800 tests were performed with a minimum of two repetitions. Tests were performed at $10^{-2}$ and $10^{-1} \mathrm{~s}^{-1}$ and for the DP600 at $25^{\circ} \mathrm{C}(\mathrm{RT}), 300,350,400$, and $500^{\circ} \mathrm{C}$, while for the DP800 at $25,300,400,450$, and $500^{\circ} \mathrm{C}$.

\section{Results and discussion}

\subsection{Calculation of yield point of strain-stress curves}

Many engineering materials, such as ductile steels typically do not manifest an evident yield strength. To identify the yield point of those materials, the $0.2 \%$ or 0.002 strain point on the engineering stress-strain diagram was determined, and then a parallel line with the same slope was drawn to the linear zone. The yield strength at $0.2 \%$ (or 0.002 ) was obtained by finding the intersection of this parallel line with the engineering stress-strain curve. Finally, the value on the vertical axis corresponding to the intersection denoted the $0.2 \%$ yield point, as shown in Fig. 3. Here, image analysis software (Image J) was employed to examine diagrams obtained from the tensile test machine and to generate supplementary drawings on diagrams in accordance with the $0.2 \%$ yield point determination. A representative image is presented in Fig. 3 as well as a small inset table indicating the yield point, in which Number 1 demonstrates the slope of the linear zone, while Number 2 (value in the red circle) indicates the yield strength.

\subsection{Mechanical properties at the 0.1 and $1 s^{-1}$ strain rates and different temperatures}

\subsubsection{Mechanical properties of DP600}

The mechanical properties of high-strength DP600 at different temperatures and strain rates were determined. Engineering stress and strain graphs obtained from the tensile tests are presented in Fig. 4. The mechanical properties obtained from the tensile tests are given in Table 2.

It is a general observation for most commercial steels that as hardness declines as a function of higher tempering temperatures, the material manifests softening and ductility with the increasing temperature. This is in good agreement with the expectation for 400 and $500^{\circ} \mathrm{C}$, yet the case for 300 and $350^{\circ} \mathrm{C}$ was reversed. The material exhibited resistance to thermal softening between 300 and $350^{\circ} \mathrm{C}$. The strength of the material heat-treated at 300 and $350^{\circ} \mathrm{C}$ was close to the test values for room temperature. Under test conditions, DP600 showed a DSA characteristic at both $0.1 \mathrm{~s}^{-1}$ and $1 \mathrm{~s}^{-1}$ strain rates resulting from the discontinuous plastic flow. Figure 4 clearly shows that the steel specimens at both strain rate values displayed DSA at 300 and $350{ }^{\circ} \mathrm{C}$, contradicting established theories on DSA. However, from room temperature up to $350^{\circ} \mathrm{C}$, there was no significant differentiating trend. The values of the strain rate at RT, 300, 400 , and $500{ }^{\circ} \mathrm{C}$ were measured as expected. As proven 
Table 2. Mechanical properties of DP600

\begin{tabular}{cccc}
\hline Strain rate $\left(\mathrm{s}^{-1}\right)$ & Temperature $\left({ }^{\circ} \mathrm{C}\right)$ & Yield strength $(\mathrm{MPa})$ & Tensile strength $(\mathrm{MPa})$ \\
\hline \multirow{3}{*}{0.1} & 300 & 343.9 & 543.6 \\
& 350 & 367.1 & 580.3 \\
& 400 & 222.1 & 393.0 \\
& 500 & 136.9 & 206.2 \\
\hline \multirow{2}{*}{1} & 300 & 352.8 & 575.7 \\
& 350 & 341.4 & 543.6 \\
& 400 & 277.5 & 434.5 \\
\hline
\end{tabular}
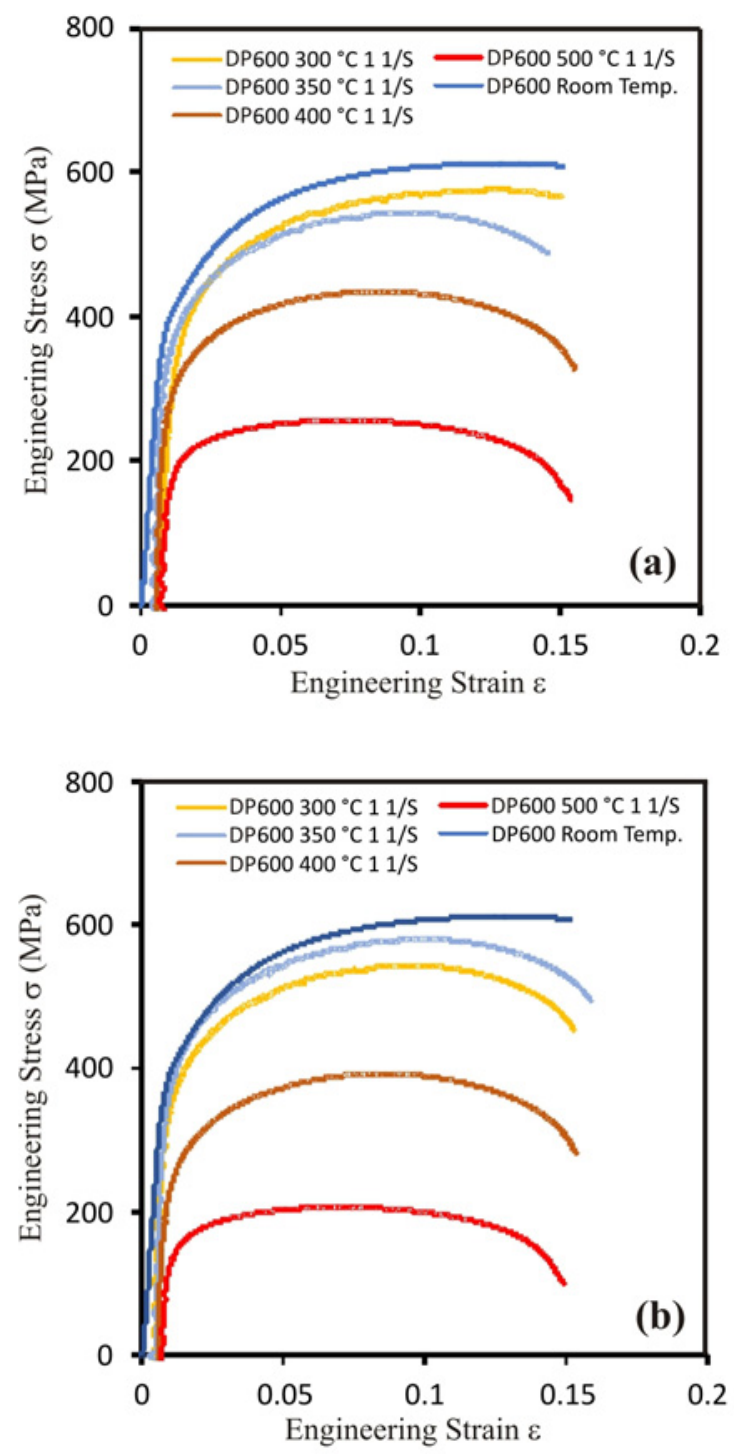

Fig. 4. The relation between stress and strain of DP600 at different temperatures and strain rates: (a) $0.1 \mathrm{~s}^{-1}$ and (b) $1 \mathrm{~s}^{-1}$.

from Fig. 4. UTS value of the material increased with increasing strain for these readings, yet the case was quite different from the others for specimens at $350^{\circ} \mathrm{C}$, which showed noticeable decrease relevant to UTS. These results were in parallel with the literature $[6$, $7,17]$. Serrations were detected at the curve obtained from the tensile tests performed at 300 and $350^{\circ} \mathrm{C}$. There were no visible serrations in the stress-strain curves of tests performed at room temperature, 400 or $500^{\circ} \mathrm{C}$. As presented in Fig. 4, for both strain rates, the DP600 material exhibited a significant softening when heated to 400 and $500{ }^{\circ} \mathrm{C}$ and facilitated by dislocation mobility.

Figure 5 shows the strain rate sensitivity of the DP600 specimens examined based on various combinations of temperatures and strain rates, taking into consideration the above discussion. It was concluded that for DP600, the strain rate mechanism had no significant impact at temperatures of 300,350 , or $400^{\circ} \mathrm{C}$. Moreover, the ductility for all tested specimens seems to have been independent of the strain rate at selected temperatures, and the value was around 0.15 . It was observed that the strain rate had a considerable effect at $500^{\circ} \mathrm{C}$, thereby improving the material strength, accompanied by a slight ductility gain. This occurrence may have stemmed from the sensitivity of the strain rate and increasing dislocation movement mostly seen at high temperatures. Also, some anomalous mechanical activities were observed when the DP600 steel was examined at 0.1 and $1 \mathrm{~s}^{-1}$ strain rates for 300 and $350^{\circ} \mathrm{C}$. The DP600 test specimen gained strength with increasing strain rates for $300^{\circ} \mathrm{C}$, while at $350^{\circ} \mathrm{C}$ the specimen softened depending on increasing strain rates. Figures 5a,b show serrations occurring at all stress-strain curves, while they are more evident at $300{ }^{\circ} \mathrm{C}$ for both strain rates. However, the serrations disappear at both strain rates at 400 and $500^{\circ} \mathrm{C}$. These abnormal activities for 300 and $350{ }^{\circ} \mathrm{C}$ may have resulted from DSA, which has the strongest effect on deformation behavior at a constant temperature range.

Variation of tensile strength, total elongation, and uniform strain against temperatures for each strain rate sequence is shown in Fig. 6. It is evident that there was strong resistance to thermal softening at 0.1 and $1 \mathrm{~s}^{-1}$ strain rates up to $350{ }^{\circ} \mathrm{C}$ (Fig. 6a). There is a dramatic decrease in the trend of strengthening be- 

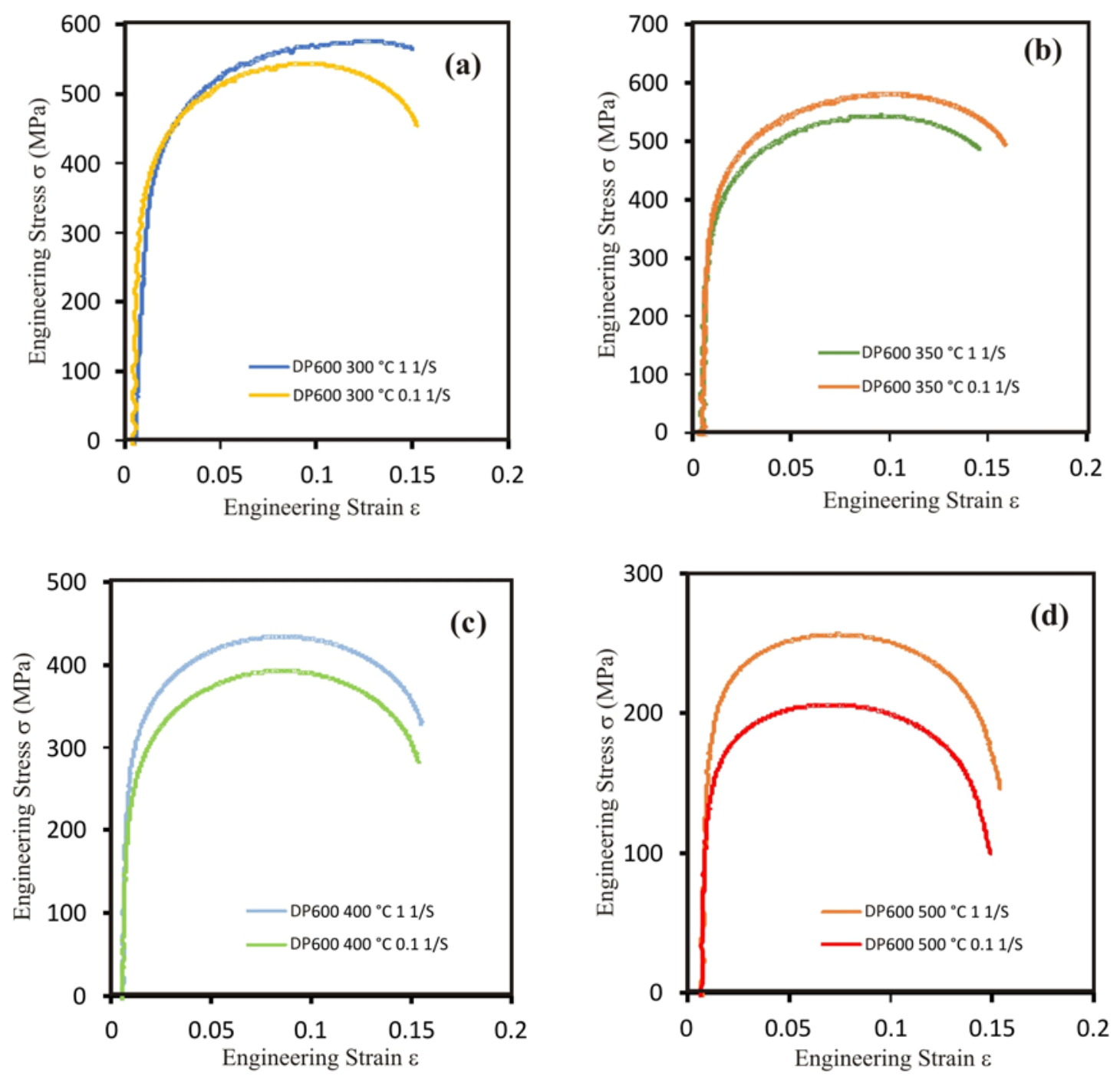

Fig. 5. Stress-strain curves of DP600 at different temperatures and strain rates.

ginning from $400{ }^{\circ} \mathrm{C}$, and the minimum value seems to be nearly $200 \mathrm{MPa}$ for the specimen tested at $0.1 \mathrm{~s}^{-1}$ and $500{ }^{\circ} \mathrm{C}$. However, the UTS values in their test pair are quite close to each other and at the $1 \mathrm{~s}^{-1}$ strain rate, the UTS of the specimens had slightly higher values than expected for $350^{\circ} \mathrm{C}$. When we look at Fig. $6 \mathrm{~b}$, there is no meaningful differentiation on the total strain bars as they accumulate around 0.15 , yet the slight gaps are always in favor of the ones tested at $0.1 \mathrm{~s}^{-1}$.

Our results also indicated that the uniform strain of DP600 declined with increasing temperature after $350^{\circ} \mathrm{C}$. Figure $6 \mathrm{c}$ clearly shows that uniform strain manifests a minimal dependence on the strain rate in each test pair; however, the maximum percent of loss in uniform elongation is at $500^{\circ} \mathrm{C}$, amounting to almost $25 \%$ in comparison with lower temperatures, proving thermal dependence at higher temperatures.

The strain hardening results of DP600 based on testing strain rates are compared in Fig. 7 . In this phenomenon, the material gained strength due to the dislocation movement. It is evident that as testing temperature gradually increased, the hardening rate at first slightly decreased and was nearly the same for 300 and $350{ }^{\circ} \mathrm{C}$ in each graph, whereas, at 0.02 engineering strain, the work hardening rate on both graphs reached the maximum around 3700 and $3750 \mathrm{MPa}$, respectively. It was concluded that these abnormalities for 300 and $350^{\circ} \mathrm{C}$ were due to the DSA mechanism, which is true for a specific temperature range. The specimens were then heated up to $500^{\circ} \mathrm{C}$ at constant rates ( 0.1 and $1 \mathrm{~s}^{-1}$, respectively) and a dramatic decrease in engineering stress-strain hardening was seen. In the comparison of the hardening in the two engineering strain graphs, the increasing strain rate resulted in lower work hardening.

\subsubsection{Mechanical properties of DP800}

Mechanical properties of high-strength DP800 

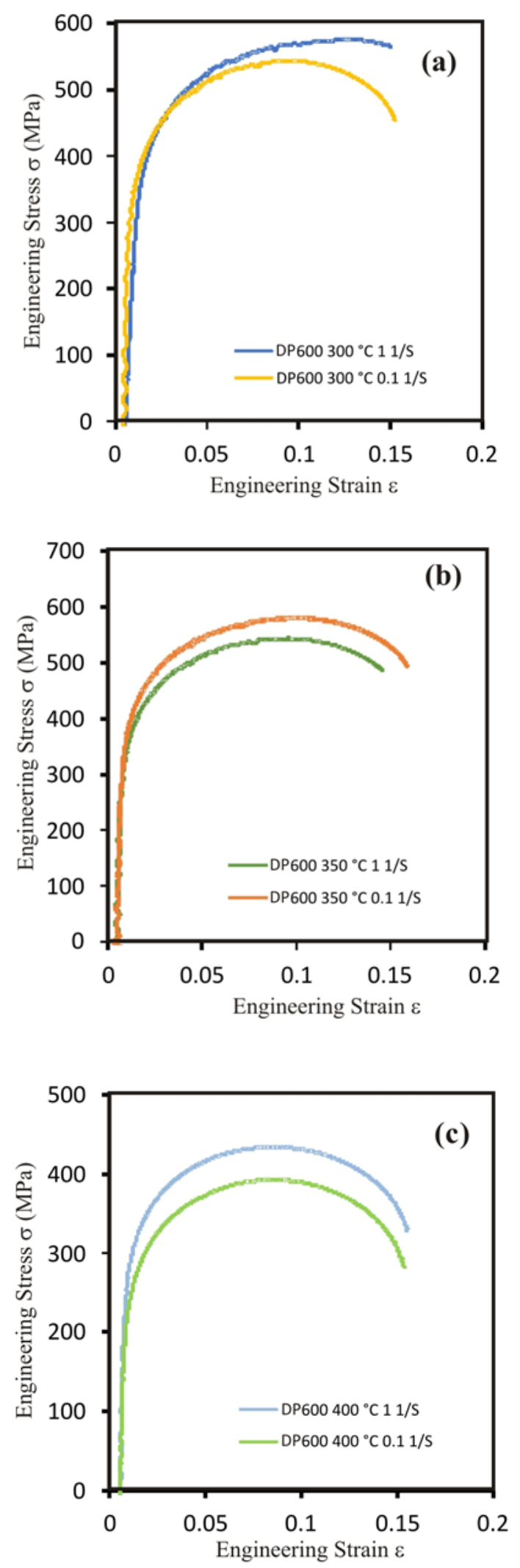

Fig. 6. Assessment of DP600 test specimens at $0.1 \mathrm{~s}^{-1}$ and $1 \mathrm{~s}^{-1}$ and $300,350,400$, and $500^{\circ} \mathrm{C}$, respectively: (a) UTS, (b) total elongation, and (c) uniform strain.
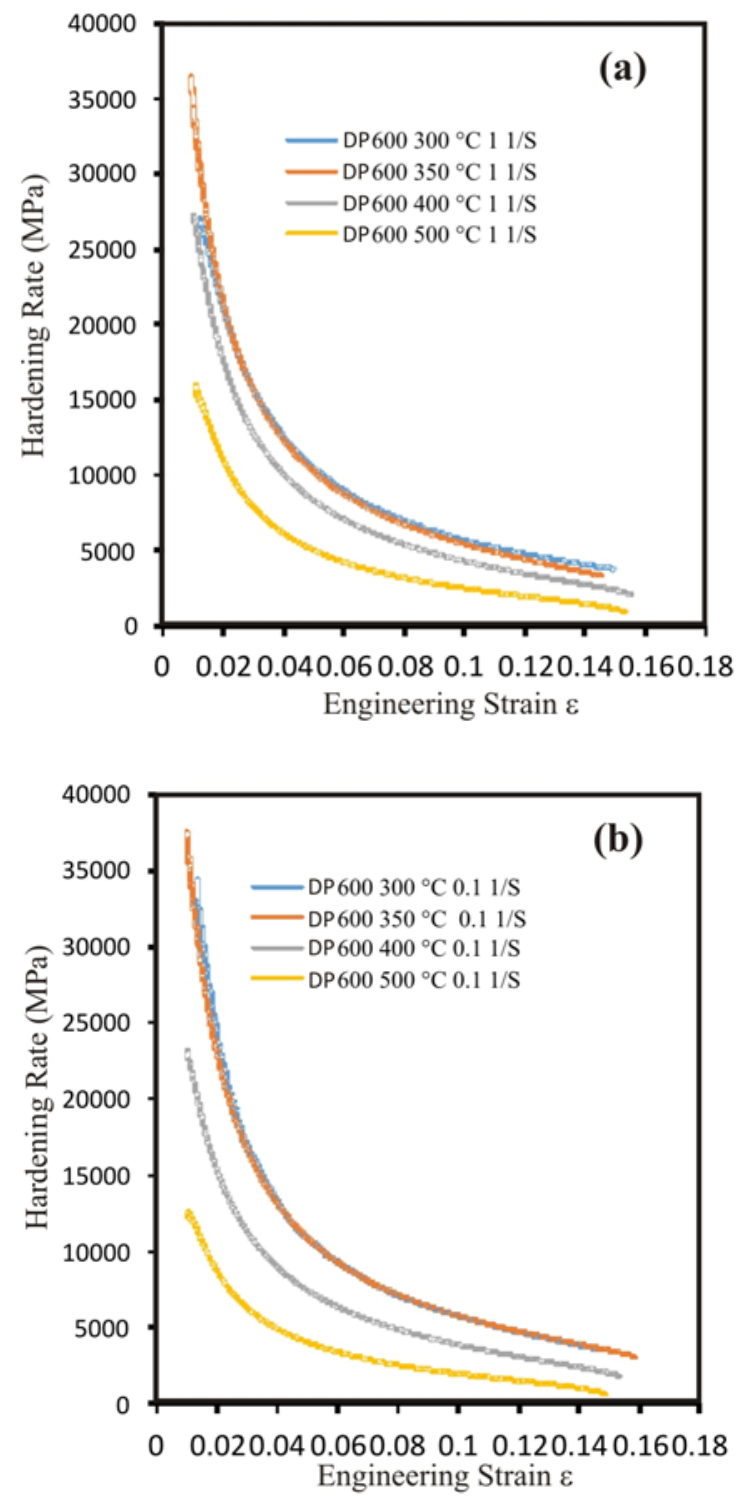

Fig. 7. Relation of temperature and hardening rate: (a) $0.1 \mathrm{~s}^{-1}$ and (b) $1 \mathrm{~s}^{-1}$.

steel at different temperatures and strain rates were determined. Engineering stress and strain data obtained from the tensile tests are given in Fig. 8. The mechanical properties obtained from tensile tests are presented in Table 3 .

As both temperature and strain rate increased, the ductility of the DP800 specimen decreased, as seen in Fig. 8. This observation is in good agreement with the literature $[17,18]$. There was significantly more thermal softening and an increase in ductility at 400 , 450 , and $500^{\circ} \mathrm{C}$ than at room temperature and $300^{\circ} \mathrm{C}$. Under the test conditions, no DSA, characterized by discontinuous plastic flow, was observed in the DP800 specimen (see Fig. 8). However, when the specimen was tested at 400 and $450^{\circ} \mathrm{C}$ and a constant strain 
Table 3. Mechanical properties of DP800

\begin{tabular}{cccc}
\hline Strain rate $\left(\mathrm{s}^{-1}\right)$ & Temperature $\left({ }^{\circ} \mathrm{C}\right)$ & Yield strength $(\mathrm{MPa})$ & Tensile strength $(\mathrm{MPa})$ \\
\hline \multirow{2}{*}{0.1} & 300 & 502.1 & 703.6 \\
& 400 & 351.9 & 550.2 \\
& 450 & 292.1 & 423.6 \\
\hline & 500 & 237.3 & 337.5 \\
\hline
\end{tabular}
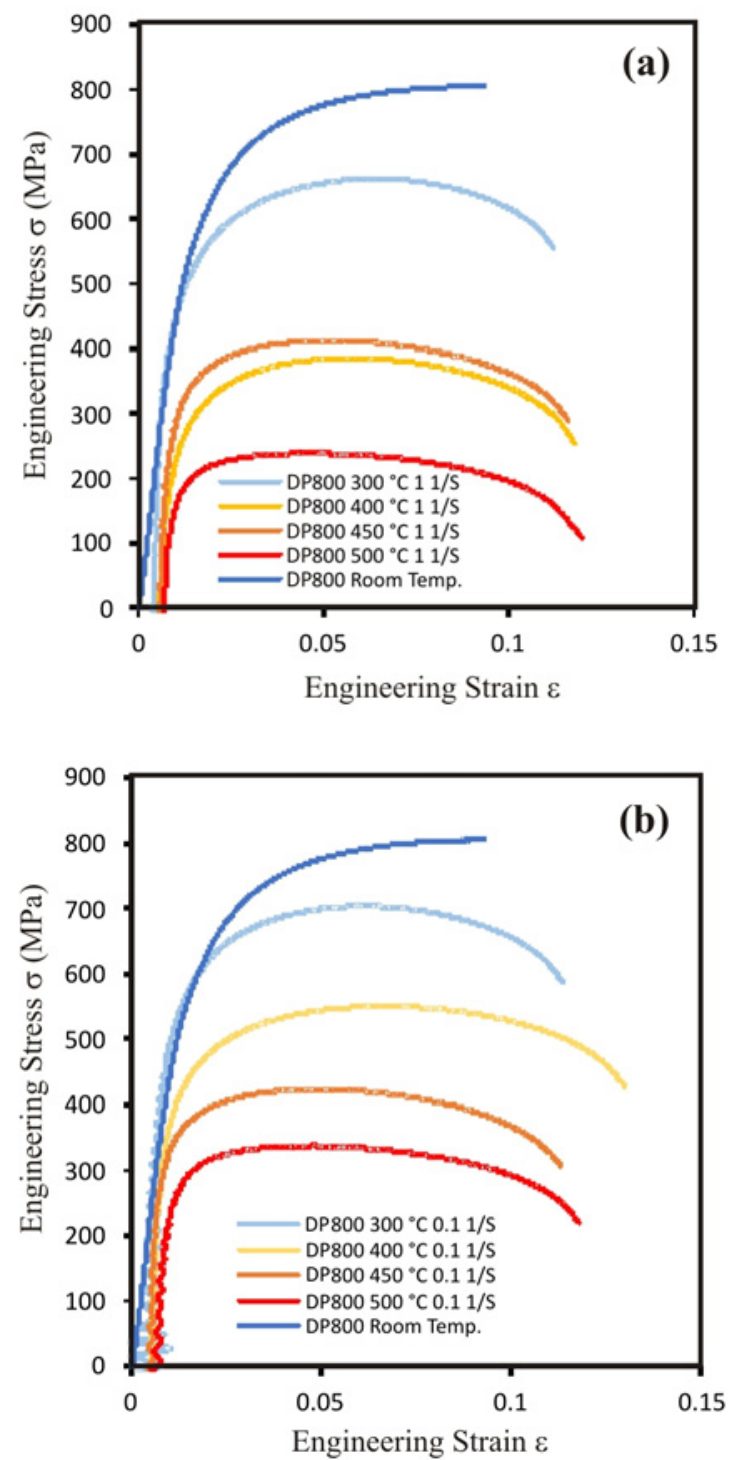

Fig. 8. The relation between stress and strain of DP800 at different temperatures and strain rates: (a) $0.1 \mathrm{~s}^{-1}$ and (b) $1 \mathrm{~s}^{-1}$.

rate of $1 \mathrm{~s}^{-1}$, the thermal softening rates were quite close to each other. These abnormalities, displayed in
Fig. 8b, suggest that DSA may control the mechanical behavior between 400 and $450^{\circ} \mathrm{C}$ in DP800.

The strain rate sensitivity and strengthening effect for the DP800 specimen was also examined at various strain rates and temperatures (see Fig. 9). Figure 9 shows that the strain rate had no significant effect on the DP800 steel at 300 and $450{ }^{\circ} \mathrm{C}$, yet the case was completely different at 400 and $500^{\circ} \mathrm{C}$, where the strain rate had noticeable impacts. With the increase in strain, the strength rate dramatically decreased. Moreover, as seen in Fig. 9, the ductility for all tested specimens seemed to be independent of the strain rate at selected temperatures, and the value was about 0.125 , except for the ones tested at $400^{\circ} \mathrm{C}$, which were around 0.14 . It was observed that the strain rates $\left(0.1\right.$ and $\left.1 \mathrm{~s}^{-1}\right)$ slightly affected the tensile strength at 300 and $450^{\circ} \mathrm{C}$, but still, there was a rising trend of decrease from 1 and $0.1 \mathrm{~s}^{-1}$. However, the case was quite the opposite with the samples tested at 400 and $500^{\circ} \mathrm{C}$, which noticeably decreased as the strain rates escalated. The material strength was accompanied by a slight ductility gain. Similar to the mechanism seen in DP600, it was suggested that this occurrence resulted from the sensitivity of the strain rate and increasing dislocation movement mostly seen at high temperatures. Also, unlike the curves at specific strain rates for DP600, there was no serration kinetics resulting from DSA on the stress-strain curves.

Flow stress values at various strain rates and temperatures for DP600 and DP800 are presented in Figs. 5 and 9, respectively. In the literature, dualphase steels have been shown to exhibit established properties following the tensile test loading up to $300^{\circ} \mathrm{C}$. When DP steels were heat-treated at 100, 200, and $300^{\circ} \mathrm{C}$, it was found that mechanical behavior such as yield strength and ultimate yield strength decreased at $100^{\circ} \mathrm{C}$ and increased at $200^{\circ} \mathrm{C}$ [15].

Figure 10 presents the variation of tensile strength, total elongation, and uniform strain against temperature for each strain rate sequence. With an increase in temperature, tensile strength steadily decreased at a strain rate of $0.1 \mathrm{~s}^{-1}$, yet this trend showed some irregularity where tensile strength at $450^{\circ} \mathrm{C}$ was slightly above that tested at $400^{\circ} \mathrm{C}$. It is evident that there was 

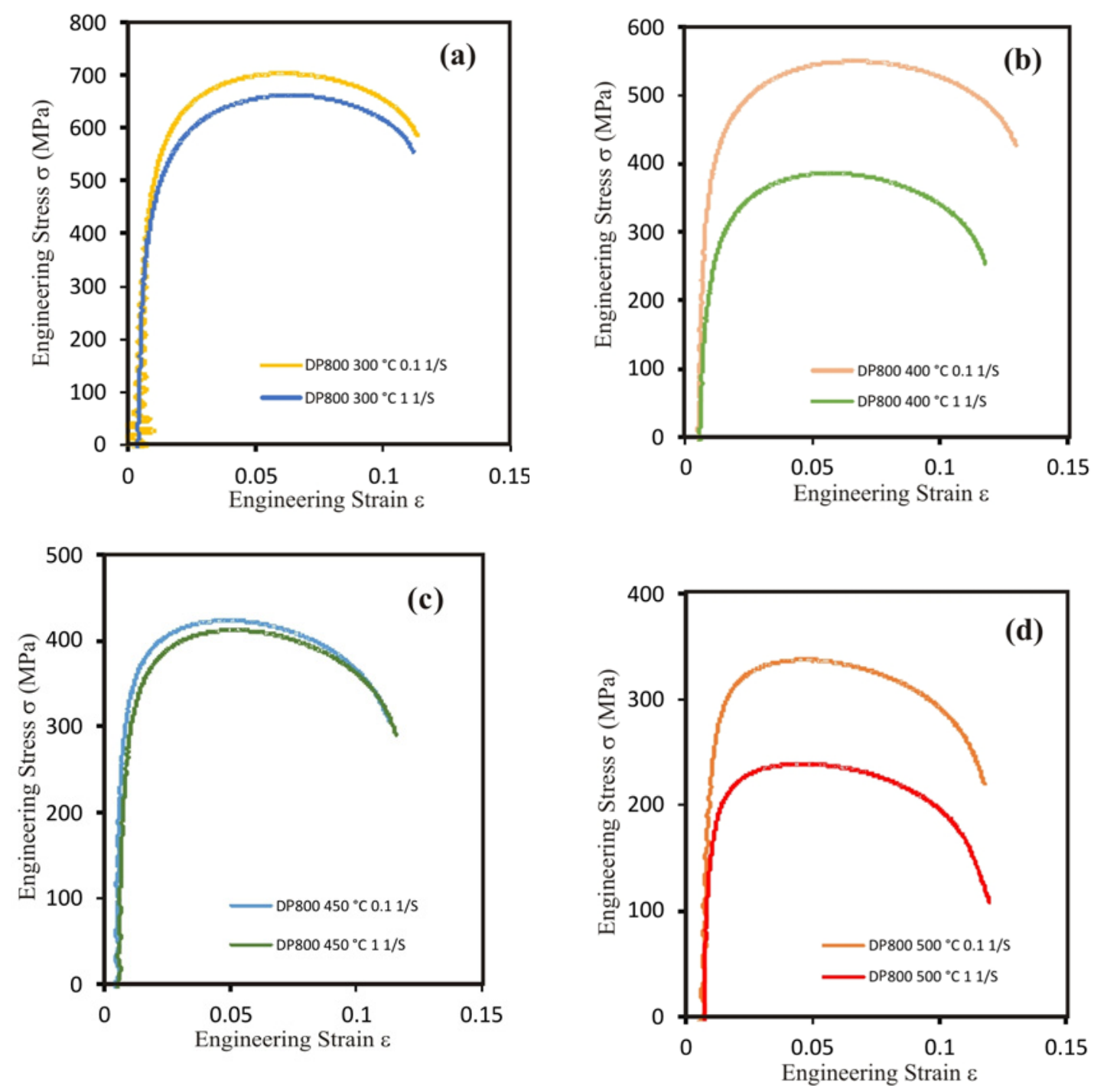

Fig. 9. Stress-strain curves of DP800 under different temperatures and strain rates.

strong resistance to ductility change at both 0.1 and $1 \mathrm{~s}^{-1}$ strain rates for all testing temperatures except for a slight increase with the sample tested at $400{ }^{\circ} \mathrm{C}$ and $0.1 \mathrm{~s}^{-1}$. There was a remarkable decrease in uniform strain rates with an increase in temperature. A steady downward trend from left to right is evident in Fig. 10c, except for the specimen tested at $400^{\circ} \mathrm{C}$ and $0.1 \mathrm{~s}^{-1}$ which broke this trend by remaining above 0.06 .

Strain hardening rates of specimens of DP800 at different temperatures based on testing strain rate are compared in Fig. 11. As seen in DP600, the material gained strength due to the dislocation movement. With the increase in temperature, the hardening rate decreased. Parallel to this, as the deformation rate increased, the hardening rate dropped sharply at first and then decreased gradually. However, DP800 specimens tested at 400 and $450^{\circ} \mathrm{C}$ for the $1 \mathrm{~s}^{-1}$ strain rate and at 450 and $500{ }^{\circ} \mathrm{C}$ for $0.1 \mathrm{~s}^{-1}$ exhibited curves that were quite close to each other, suggesting that at specific strain rate and temperature combinations there was no meaningful effect on the hardening rate. In the comparison of hardening in the two engineering strain graphs, an increasing strain rate resulted in decreased hardening.

\subsection{Comparison of DP600 and DP800 steels and their possible applications}

Figure 12 presents the variation of UTS at various temperatures for each grade of steel. Both DP600 and DP800 steels manifested ordinary responses to an increasing temperature at a constant strain of 1 and $0.1 \mathrm{~s}^{-1}$. Figure 12 clearly shows the UTS data in a descending trend for both grades of steel. However, there were still some abnormalities recorded as the DSA mechanism occurred at certain temperatures during the tensile test. These effects were more visible 

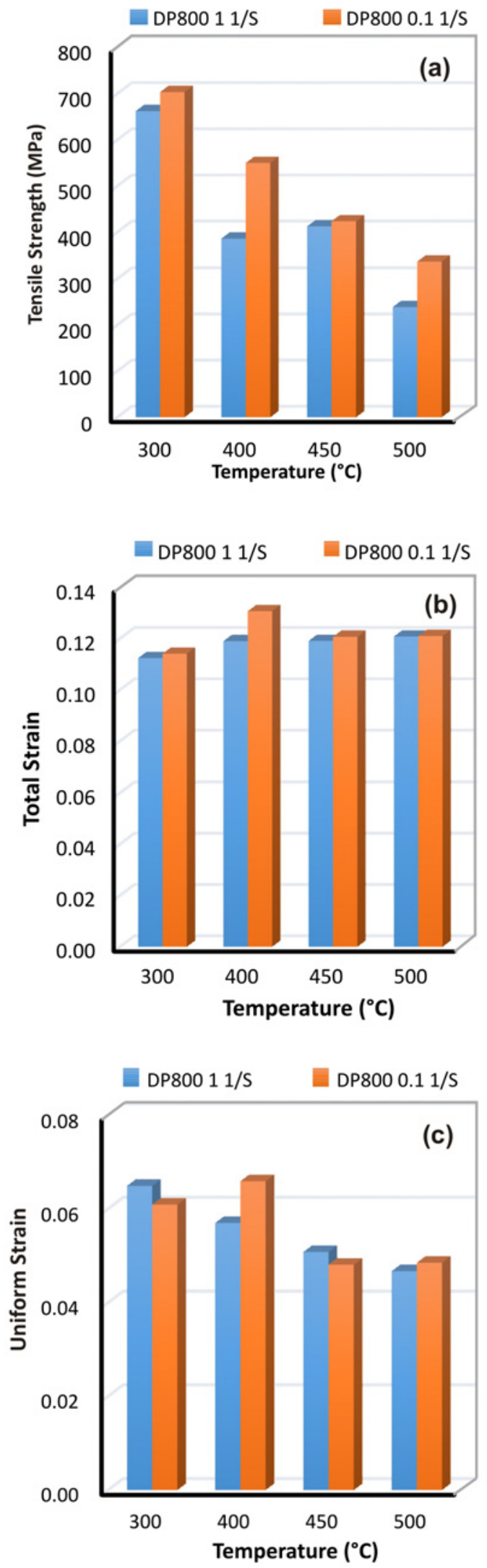

Fig. 10. Assessment of DP800 test specimens at $0.1 \mathrm{~s}^{-1}$ and $1 \mathrm{~s}^{-1}$ and $300,400,450$, and $500^{\circ} \mathrm{C}$, respectively: (a)

UTS, (b) total elongation, and (c) uniform strain.
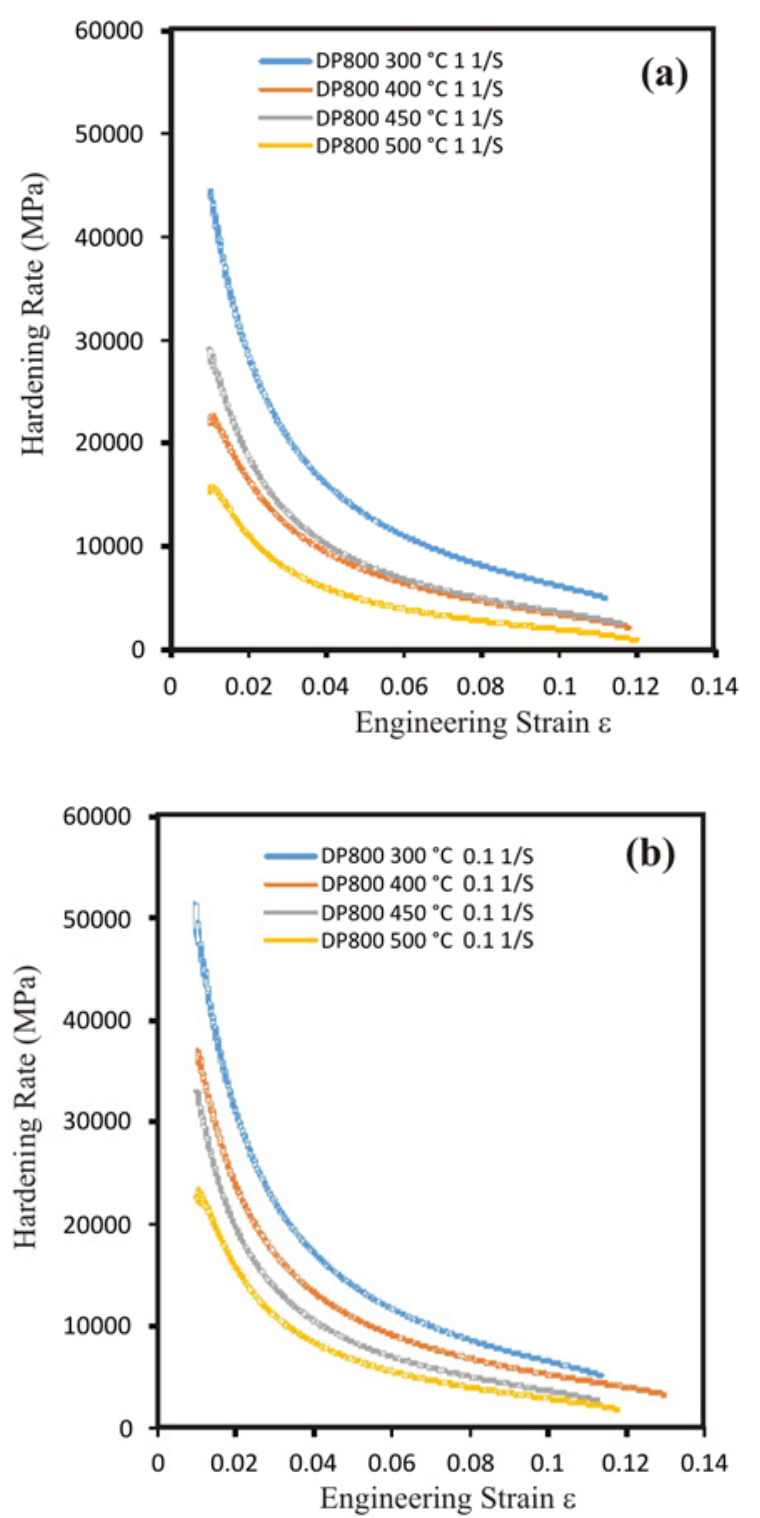

Fig. 11. Relation of temperature and hardening rate: (a) $0.1 \mathrm{~s}^{-1}$ and (b) $1 \mathrm{~s}^{-1}$.

at $350^{\circ} \mathrm{C}$ for DP600 steel where the resulting trend bent towards a strength gain, especially at a strain rate of $0.1 \mathrm{~s}^{-1}$. This occurrence was true for DP800 steel under testing at $450^{\circ} \mathrm{C}$, which showed a high amount of contradiction, although when the testing was carried out at higher temperatures, the tensile curves overcame those abnormalities and recovered the linear decreasing trend. In addition to these readings, curves at 1 and $0.1 \mathrm{~s}^{-1}$ generated by the tensile testing machine were almost parallel, indicating that the difference in ferrite and martensite composition determined at which temperature and strain rate the DSA mechanism occurred. When DP600 specimens were heated at 300 and $350^{\circ} \mathrm{C}$, some abnormalities in 

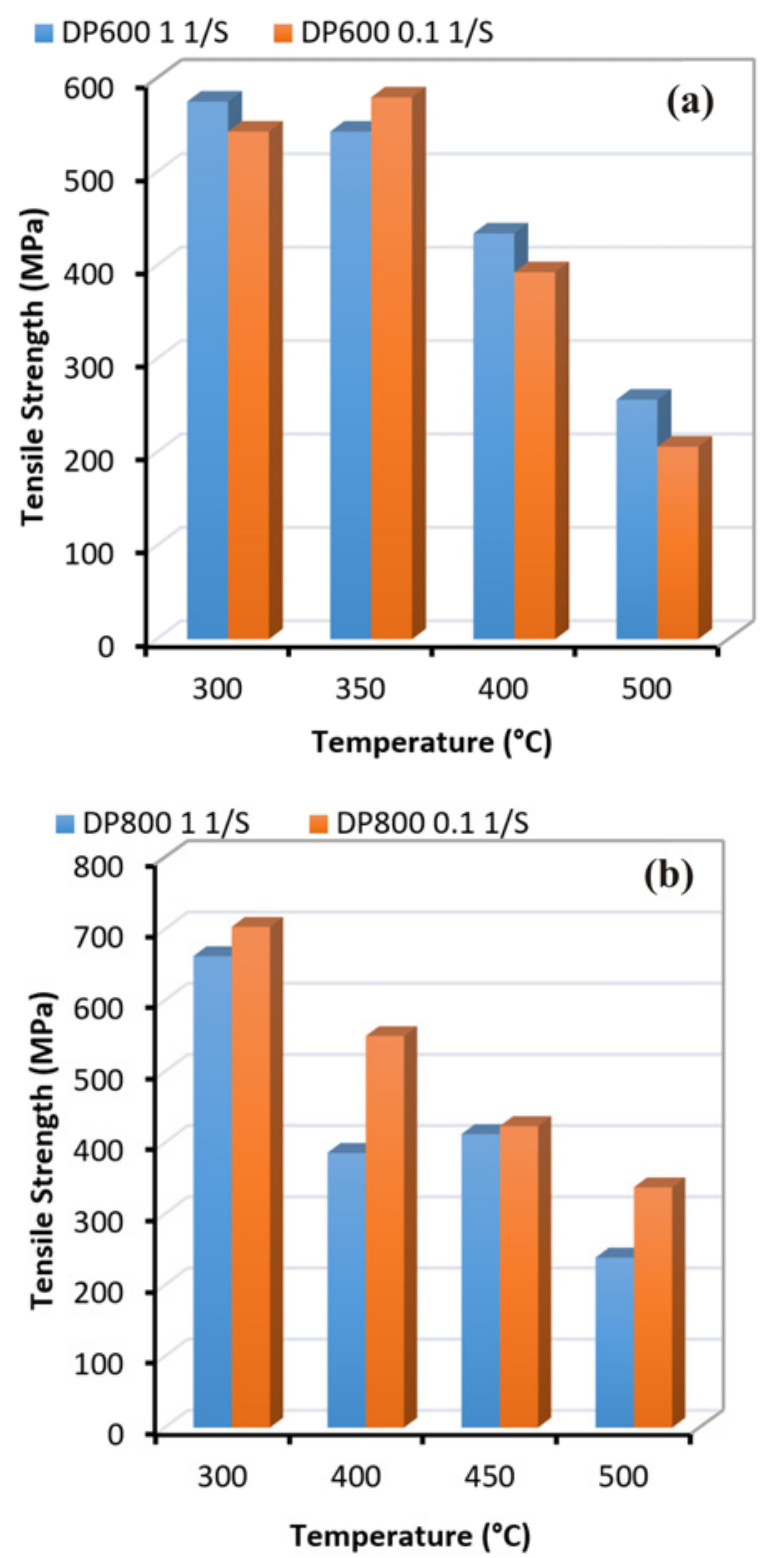

Fig. 12. Comparison of the ultimate tensile strength of DP600 and DP800 steels dependent on increasing temperature conditions.

the form of serrations were seen. Under these testing conditions, thermal softening appeared weak, and the curves were quite close to each other, whereas serrations were mostly absent in the DP800 stress-strain curves. However, as with DP600 at certain temperatures, the stress-strain curves became closer to each other at 300 and $450^{\circ} \mathrm{C}$, indicating that DSA still existed at these temperatures in warm forming even though no serrations appeared on the curves in question.

With an increase in temperature and strain rate, the uniform strain noticeably decreased for both, and this may have resulted in premature necking formation followed by early unstable plastic deformation. Therefore, the pre-heating (warm forming) range should be carefully determined for these steels, depending on the application area. There is a close relationship between structural composition (ferrite and martensite fraction), thermal conditions, and work hardening in the warm forming process. Fundamentally, the warm forming process is required to avoid unfavorable events such as tearing and instant cracking. The extent of the change in the mechanical behavior and the resistance to defects greatly depend on the temperature and strain rate to which the DP steels are subjected. Moreover, as well as the composition of the steel, the length of the duration at the selected temperature plays a decisive role in the formability phenomenon.

\section{Conclusions}

In this study, the micromechanical behavior of two distinct grades of DP steels was subjected to experimental investigation. Satisfactory predictions of the mechanical behavior of DP600 and DP800 steels with different microstructural patterns in terms of their ferrite/martensite combination were achieved using a new local heating method introduced into the experimental unit. Thermo-mechanical testing of DP600 and DP800 steels was performed from room temperature to $500{ }^{\circ} \mathrm{C}$ and at strain rates of 1 and $0.1 \mathrm{~s}^{-1}$. The findings are summarized below:

1. Yield and tensile strength dramatically decreased depending on increasing temperature for DP600 steel, specifically at temperatures of 400 and $500{ }^{\circ} \mathrm{C}$, while the case was true for DP800 steel at 400,450 , and $500^{\circ} \mathrm{C}$. However, there was no noticeable change in yield or tensile strength for DP600 steel at the temperatures of 300 and $350^{\circ} \mathrm{C}$ or for DP800 steel at the temperature of $300^{\circ} \mathrm{C}$.

2. For DP600 steel specimens, serrations resulting from DSA kinetics appeared at 300 and $350^{\circ} \mathrm{C}$, causing disadvantages regarding formability capacity, whereas the case was different for DP800 steel, which showed no serrations. However, DSA still existed in the structure at the temperatures of 300 and $450^{\circ} \mathrm{C}$, indicating a resistance to the change in thermal softening.

3 . The effect of the strain rate was at a negligible level for DP600 steel at the temperatures of 300, 350, and $400^{\circ} \mathrm{C}$, while it was evident at $500^{\circ} \mathrm{C}$. Likewise, the strain rate had no significant impact on DP800 steel at 300 and $450^{\circ} \mathrm{C}$; however, the strain rate effect played an important role at 400 and $500{ }^{\circ} \mathrm{C}$.

4. In the hot tensile tests, the maximum hardening rate was observed at the temperatures of $350^{\circ} \mathrm{C}$ for DP600 and DP 800 at $300^{\circ} \mathrm{C}$.

5 . To increase the LDR ratio in warm deep drawing applications, the optimum process point at the temperature spectrum was determined at $400^{\circ} \mathrm{C}$ with DP600 
steel at which the yield point decreased significantly, and the ductility increased; for DP800 the case was true at the temperatures of 400 and $450{ }^{\circ} \mathrm{C}$.

These findings on the behavior of DP600 and DP800 steels experimentally obtained under thermo-mechanical tensile loading are acceptable and may well reflect their potential applications, especially for automobile body components.

\section{Acknowledgements}

The author gratefully acknowledges the financial support provided by the Düzce University Research Fund (Project No: 2016.06.05.457).

\section{References}

[1] J. Qin, R. Chen, X. Wen, Y. Lin, M. Liang, F. Lu, Mechanical behaviour of dual-phase high-strength steel under high strain rate tensile loading, Mater Sci Eng A 586 (2013) 62-70. doi:10.1016/j.msea.2013.07.091

[2] M. S. Shahriary, B. Koohbor, K. Ahadi, A. Ekrami, M. Khakian-Qomi, T. Izadya, The effect of dynamic strain aging on room temperature mechanical properties of high martensite dual phase (HMDP) steel, Mater Sci Eng A 550 (2012) 325-332. doi:10.1016/j.msea.2012.04.082

[3] S. K. Akay, M. Yazici, A. Bayram, A. Avinc, Fatigue life behaviour of the dual-phase low carbon steel sheets, J Mater Process Tech 209 (2009) 3358-3365. doi:10.1016/j.jmatprotec.2008.07.038

[4] X. Zuo, Y. Chen, M. Wang, Study on microstructures and work hardening behavior of ferrite-martensite dual-phase steels with high-content martensite, Mat. Res 15 (2012) 915-921. doi:10.1590/S1516-14392012005000118

[5] O. Çavuşoğlu, A. Güral, H. Gürün, Influence of strain rate on tensile properties and fracture behaviour of DP600 and DP780 dual-phase steels, Ironmaking and Steelmaking 44 (2017) 773-781. doi:10.1080/03019233.2016.1232911

[6] H. Huh, S. B. Kim, J. H. Song, J. H. Lim, Dynamic tensile characteristics of trip-type and dp-type steel sheets for an auto-body, Int J Mech Sci 50 (2008) 918931. doi:10.1016/j.ijmecsci.2007.09.004

[7] N. Tsuchida, Y. Izaki, T. Tanaka, K. Fukaura, Effects of temperature and strain rate on stress-strain curves for dual-phase steels and their calculations by using the kocks-mecking model, ISIJ International 52 (2012) 729-734. doi:10.2355/isijinternational.52.729
[8] N. D. Beynon, S. Oliver, T. B. Jones, G. Fourlaris, Tensile and work hardening properties of low carbon dual phase strip steels at high strain rates, MATER SCI TECH 21 (2005) 771-778. doi:10.1179/174328405X41038

[9] S. Oliver, T. B. Jones, G. Fourlaris, Dual phase versus TRIP strip steels: Microstructural changes as a consequence of quasi-static and dynamic tensile testing, Mater Charact 58 (2007) 390-400. doi:10.1016/j.matchar.2006.07.004

[10] A. Ch. Darabi, H. R. Chamani, J. Kadkhodapour, A. P. Anaraki, A. Alaie, M. R. Ayatollahi, Micromechanical analysis of two heat-treated dual phase steels: DP800 and DP980, Mech Mater, 110 (2017) 68-83. doi:10.1016/j.mechmat.2017.04.009

[11] R. R. U. Queiroz, F. G. G. Cunha, B. M. Gonzalez, Study of dynamic strain aging in dual phase steel, Mater Sci Eng A 543 (2012) 84-87. doi:10.1016/j.msea.2012.02.050

[12] S. Gündüz, A. Tosun, Influence of straining and ageing on the room temperature mechanical properties of dual phase steel, Materials and Design 29 (2008) 1914-1918. doi:10.1016/i.matdes.2008.04.028

[13] O. Çavuşoğlu, H. Gürün, Investigation of the effects of deformation speed on the mechanical properties and deep drawing process of DP600 and DP780 sheet metal, Journal of the Faculty of Engineering and Architecture of Gazi University 29 (2014) 777-784. (in Turkish)

[14] T. Pepelnjak, E. Kayhan, B. Kaftanoglu, Analysis of non-isothermal warm deep drawing of dual-phase DP600 steel, Int J Mater Form 12 (2019) 223-240. doi:10.1007/s12289-018-1400-0

[15] O. Çavusoglu, H. Gürün, S. Toros, A. Güral, Strain rate sensitivity and strain hardening response of DP1000 dual phase steel, Metall Res Technol 115 (2018) 507. doi:10.1051/metal $/ 2018016$

[16] E. Kayhan, B. Kaftanoglu, Experimental investigation of non-isothermal deep drawing of DP600 steel, Int J Adv Manuf Tech 99 (2018) 695-706. doi:10.1007/s00170-018-2403-1

[17] B. Bayramin , C. Şimşir, M. Efe, Dynamic strain aging in DP steels at forming relevant strain rates and temperatures, Mater Sci Eng A 704 (2017) 164-172. doi:10.1016/j.msea.2017.08.006

[18] A. S. Khan, M. Baig, S. H. Choi, H. S. Yang, X. Sun, Quasi-static and dynamic responses of advanced high strength steels: Experiments and modeling, Int J Plasticity 30-31 (2012) 1-17. doi:10.1016/j.ijplas.2011.08.004 